\title{
Design and Evaluation of a Delivery System Based on Liposomes for Armoracia rusticana Extract
}

\begin{abstract}
RAMONA-DANIELA PAVALOIU ${ }^{1,2 *}$, FAWZIA SHA'AT ${ }^{1,2}$, CORINA BUBUEANU ${ }^{1}$, CRISTINA HLEVCA ${ }^{1}$ GHEORGHE NECHIFOR ${ }^{2 *}$
${ }^{1}$ National Institute for Chemical-Pharmaceutical Research and Development - ICCF Bucharest,112 Calea Vitan, 031299, Romania 2University Politehnica of Bucharest, Faculty of Applied Chemistry and Materials Science,1-7 Gheorghe Polizu Str., 011061, Bucharest

The aim of this paper was the design and evaluation of delivery system for Armoracia rusticana leaves extract with the purpose to use such systems in food or cosmetic field. Liposomes loaded with Armoracia rusticana were prepared by film hydration method and presented good entrapment efficiency, nano-sizes $(<150 \mathrm{~nm})$, low polydispersity index and good stability over 90 days at $4^{\circ} \mathrm{C}$. In vitro drug release study showed the ability of liposomes to provide slow release of extract with reduced burst effect compared to free extract. These promising results suggest that liposomes could be exploited as carriers for herbal ingredients.
\end{abstract}

Keywords: Armoracia rusticana, liposomes, drug delivery systems, encapsulation

Liposomes are self-organizing colloidal nanoparticles which contain an aqueous inner compartment with $25 \mathrm{~nm}$ $-2.5 \mu \mathrm{m}$ molecules, separated by one or more lipid bilayers, composed of amphiphilic phospholipids. Liposomes can encapsulate both hydrophobic and hydrophilic compounds due to the amphiphilic nature of phospholipids, unlike other carriers, which can load compounds having only specific characteristics. Apart from this feature they possess biodegradability, biocompatibility, non-toxicity, nonimmunogenicity and have been extensively used in pharmaceutical, food and cosmetic industries [1-4].

Liposomes have been employed as an effective method to encapsulate natural compounds and whole plant extracts to improve stability, solubility, and therefore bioavailability [5]. Other carriers like: micro-/nanoemulsions, microspheres, micro-/nanoparticles, have been also successfully applied as carries [6,7]. The advantages of encapsulation in liposomes are: better absorption, decrease of toxicity and side effects, decrease of administration frequency, decrease of administration dose and increase of therapeutic effectiveness [8-10]. Several preparation methods of liposomes loaded with plant extracts or natural compounds were described in literature, such as: thin-film hydration technique [11], microemulsification [12], sonication [13], reverse-phase evaporation [14] and ethanol injection [15].

The aim of the study was the design and evaluation of liposome-based system for Armoracia rusticana leaves extract with the purpose to use such systems in cosmetic field. A. rusticana, known as horseradish, is a perennial plant from the Brassicaceae family with antioxidant, antimicrobial, chemopreventive, anti-inflammatory, gastroprotective and hypocholesterolaemic effects, used in food industry and cosmetic products [16]. To fulfill the aim of this paper, liposomes loaded with $A$. rusticana were prepared by film hydration method followed by sonication and extrusion. Entrapment efficiency, particle size, polydispersity index, stability were assessed for the characterization of liposomes. The evaluation of liposomes loaded with $A$. rusticana as delivery systems was performed.

\section{Experimental part \\ Materials}

Phosphatidylcholine (PC), sodium cholate, sodium carbonate, Triton X-100, gallic acid (95\%), Folin-Ciocalteu reagent, Phosphate-Buffered Saline (PBS), were purchased from Sigma-Aldrich Co (Germany). A. rusticana (leaves) were harvested from Dambovita County, Romania, and identified by the botanical team of INCDCF-ICCF Bucharest. A voucher specimen, coded as AR leaves AA2016 was stored at INCDCF-ICCF Plant MateriaTStoring Room. An A. Rusticana leaves extract in 50\% (v/v) ethanol was used in this study; the extraction procedure was: forty grams (40 g) of raw material, shade dried at room temperature and ground to a powder, was extracted with $500 \mathrm{~mL}$ ethanol $(50 \% \mathrm{v} / \mathrm{v})$, at reflux temperature for one hour under continuous stirring. The resulted solution was paper filtered and concentrated at $72-75 \mathrm{~mm} \mathrm{Hg}, 60^{\circ} \mathrm{C}$ and further solved in $200 \mathrm{~mL}$ ethanol (extraction yield $\sim 23.43 \%$.) The extract had a significant value for phenol content of $21.16 \pm 0.010$ $\mathrm{mg} \mathrm{GAE} / \mathrm{g}$ dry material and its main component was rutin (55\%). The extract was stored at $4^{\circ} \mathrm{C}$ until analysis.

Preparation of liposomes loaded with A. rusticana extract Liposomes loaded with $A$. rusticana were prepared using thin-film hydration method followed by sonication and extrusion. Briefly, A. Rusticana extract, phosphatidylcholine and sodium cholate (table 1) were dissolved in $10 \mathrm{~mL}$ methanol and the lipid solution was evaporated using a

\begin{tabular}{|c|c|c|c|c|c|c|}
\hline Sample code & $\begin{array}{c}\text { PC } \\
(\mathbf{m g})\end{array}$ & $\begin{array}{c}\text { Sodium } \\
\text { cholate } \\
(\mathbf{m g})\end{array}$ & $\begin{array}{c}\text { Extract } \\
(\mathbf{m g})\end{array}$ & $\begin{array}{c}\text { EE } \\
\mathbf{( \% )}\end{array}$ & $\begin{array}{c}\text { Size } \\
(\mathbf{n m})\end{array}$ & $\begin{array}{c}\text { Polydispersity } \\
\text { index }\end{array}$ \\
\hline L1 & 80 & - & - & - & $85.40 \pm 0.34$ & $0.400 \pm 0.01$ \\
\hline L2 & 80 & 20 & - & - & $105.20 \pm 2.04$ & $0.379 \pm 0.02$ \\
\hline AR_L1 & 80 & - & 25 & $79.01 \pm 0.23$ & $140.30 \pm 0.31$ & $0.343 \pm 0.03$ \\
\hline AR_L2 & 80 & 20 & 25 & $72.01 \pm 0.57$ & $138.30 \pm 0.11$ & $0.319 \pm 0.02$ \\
\hline
\end{tabular}

Table 1 COMPOSITION AND CHARACTERISTICS OF LIPID VESICLES

*email: pavaloiu_daniella@yahoo.com; doru.nechifor@yahoo.com 
rotary evaporator (Laboranta 4000 Rotary evaporator, Heidolph Instruments $\mathrm{GmbH} \& \mathrm{Co} . \mathrm{KG}$ ) for $2 \mathrm{~h}$, under vacuum, at $35^{\circ} \mathrm{C}$. After the complete solvent removal, the lipid film was hydrated for $1 \mathrm{~h}$ with distilled water at $35^{\circ} \mathrm{C}$. Obtained liposomes were left $2 \mathrm{~h}$ at room temperature for the stabilization of lipid membranes. After stabilization, the liposomes were sonicated in a sonication bath (Sonorex Digital 10P, Bandelin Electronic GmbH \& Co) filled with ice for $20 \mathrm{~min}$ and then extrudated using $0.4 \mu \mathrm{m}$ and $0.2 \mu \mathrm{m}$ pore size filters (five extrusions for each pore size) to reduce pore size. Loaded liposomes were separated from free extract by centrifugation at $10000 \mathrm{rpm}, 5^{\circ} \mathrm{C}$ for $30 \mathrm{~min}$. The clear supernatant was siphoned off carefully and the sediment was re-suspended in distilled water. This procedure of centrifugation was repeated twice. All samples were stored at $4^{\circ} \mathrm{C}$ until analysis.

\section{Characterization of liposomes loaded with A. rusticana extract}

Size and polydispersity index were measured by Dynamic Light Scattering technique (DLS) using a particle size analyzer (Beckman Coulter N4 PCSSubmicron, Coulter Company). Measurements were made at $25^{\circ} \mathrm{C}$ (detector position: angle $90^{\circ}$, solvent refractive index: 1.332; solvent viscosity: $0.871 \mathrm{cP}$ ) using 10 runs for each measurement on diluted samples (1:10). The entrapment efficiency (EE, $\%)$ was calculated using equation 1 , where $M$ was the amount of extract loaded in liposomes and $M$ was the amount of extract initially added in formulation. The amount of extract loaded in liposomes was determinated using equation 2 , as the difference of the amount of extract initially added in formulation $\left(M_{t}\right)$ and the amount of free extract $\left(M_{\mathrm{fe}}\right)$. The amount of free extract was assessed by spectrophotometry at maximum absorbance of extract using rutin calibration curve (264 $\mathrm{nm}$ wavelength; concentration range $5 \times 10^{-6}-50 \times 10^{-6} \mathrm{~g} / \mathrm{mL} ; y=6830.5 x$ $+0.0245, R^{2}=0.9992$ ).

The formulations were subjected to a stability study for a period of 90 days at a temperature of $4^{\circ} \mathrm{C}$. Samples were analyzed at 30, 60 and 90 days by evaluating extract content.

$$
\begin{aligned}
& E E(\%)=\frac{M}{M_{t}} \times 100 \\
& M=M_{t}-M_{f e}
\end{aligned}
$$

In vitro release of $A$. rusticana extract from loaded liposomes

In vitro release of $A$. rusticana extract from loaded liposomes was assessed using dialysis membrane method under sink conditions [17-19]. A sample of $1.0 \mathrm{~mL}$ loaded liposomes or free extract, was placed in a dialysis bag with 14000 molecular weight cut-off (Sigma Aldrich, USA) and immersed into $200 \mathrm{~mL}$ PBS $0.1 \mathrm{M} \mathrm{pH} \mathrm{7.4,} \mathrm{with} \mathrm{a} \mathrm{stirring}$ speed of $100 \mathrm{rpm} / \mathrm{min}$ and the temperature was maintained at $37^{\circ} \mathrm{C}$. At predetermined times $(15,30,45,60,120,180$, $240,300,360,600 \mathrm{~min}$ and $24 \mathrm{~h}$ ) samples of $1.0 \mathrm{~mL}$ were taken. After a sample collection the release medium taken was replenished with the same sample volume of fresh medium. The cumulative release rate (CDR) was calculated using equation 3 , where $Q_{n}$ was the amount of extract released at time $n$ and $Q_{t}$ was the amount of extract initially entrapped in liposomes. The amount of extract released was assessed by spectrophotometry at maximum absorbance of extract using rutin calibration curve. The mechanism of extract release was investigated by applying several kinetics models (Zero-order, First order, Higuchi and Hixson-Crowell). The models were compared using the correlation coefficient $\left(R^{2}\right)$.

$$
C D R(\%)=\frac{Q_{n}}{Q_{t}} \times 100
$$

\section{Statistical analysis}

Statistical analysis of the data was performed with SPSS 18.0 (SPSS Inc., Chicago, IL, USA). Values are represented as mean \pm standard deviation (SD) of thee replicates. Differences were considered significant at $p<0.05$.

\section{Results and discussions}

The main aim of our work was to develop a delivery system for an antioxidant plant extract based on liposomes with potential application in cosmetic field. A. rusticana (leaves) was selected as plantmaterial due to its significant antioxidant activity. Also, from our best knowledge no previous studies regarding the incorporation of $A$. rusticana leaves extract in liposomes were described in literature.

The liposomes loaded with $A$. rusticana extract were prepared using thin-film hydration method and characterizated in terms of size, polydispersity index, entrapment efficiency and stability over 90 days. The liposomes loaded with $A$. rusticana extract had good entrapment efficiency values, $79.01 \pm 0.23 \%$ for $A R$ L1 and $72.01 \pm 0.57 \%$ for AR L2, confirming that thin-film hydration method is a suitāble method for plant extract encapsulation in liposomes. Similar results were presented in other papers, eg. an entrapment efficiency of $\sim 84 \%$ for Glycyrrhiza glabra L. [20] or 88\% for grape-seed [21, 22]. Also, the liposomes loaded with $A$. rusticana were stable at $4^{\circ} \mathrm{C}$ for at least 90 days with minimal plant material loss $(\sim 0.36$ plant material loss after 30 days; $\sim 0.7$ plant material loss after 90 days). All formulations had nanometer size range, with values below $150 \mathrm{~nm}$. Also, it can be observed an increase in size at the incorporation of $A$. rusticana extract in liposomes with $\sim 33.1$ for $A R L 1$, and respectively $\sim 54.9$ for $A R L 2$. The small difference between liposomal formulations is due to the addition of sodium cholate, an edge activator that entered in competition with the extract and therefore only a smaller quantity of extract was accommodated in the liposomes containing sodium cholate, resulting in a decrease of size and entrapment efficiency. Also, all samples had polydispersity index values lower than 0.4 indicating a less pronounced tendency to aggregation.

The in vitro release of $A$. rusticana extract from liposomes was presented as cumulative percent release over an $24 \mathrm{~h}$ study period in PBS at $\mathrm{pH} 7.4,37^{\circ} \mathrm{C}, 100 \mathrm{rpm}$; the results of this study were presented in Fig. 1. The release profile from the free extract presented a burst release phenomenon with $50.65 \pm 0.13 \%$ released in the initial 30 minutes; the burst effect was restricted drastically by loading the A. Rusticana extract in liposomes (19.66 \pm $0.13 \%$ was released in the initial 30 minutes from AR L2 and respectively $34.67 \pm 0.33 \%$ from AR_L1). After 10 hour almost all amount of $A$. Rusticana from free extract was released $(98.61 \pm 1.09 \%)$, while liposomal formulations provided a much slower release, for example after 10 hours, the percentage release of extract was found out to be $67.39 \pm 3.65 \%$ and $30.51 \pm 0.32 \%$ in case of AR L1 and AR L2 formulation, respectively; ultimately after 24 hours reaching $72.98 \pm 3.90 \%$ and $48.25 \pm 3.90 \%$ for AR L1 and AR_L2 liposomes, respectively. In order to evaluate the méchanism of in vitro extract release, several 


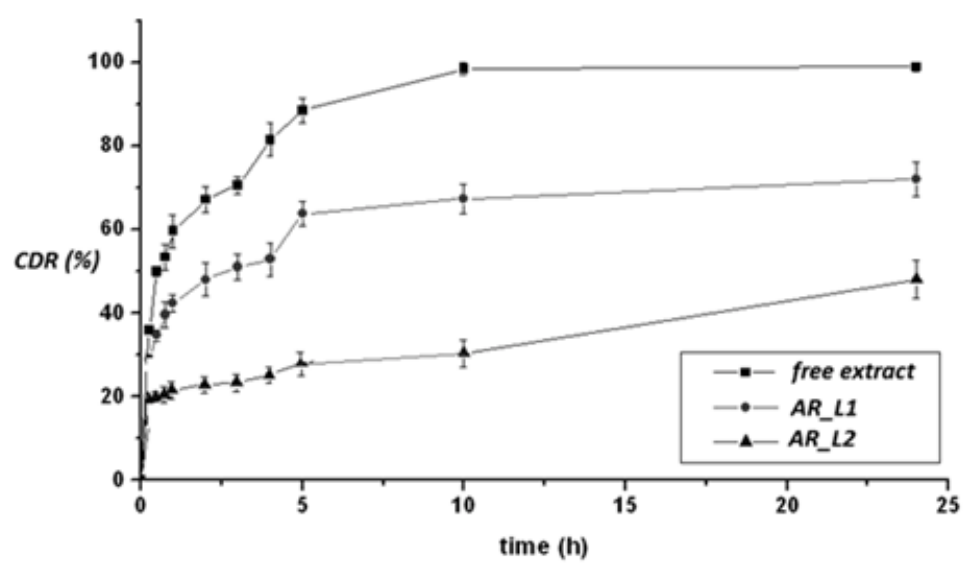

Fig. 1. Release of polyphenols from liposomes loaded with $A$. rusticana vs. free extract.

\begin{tabular}{|c|c|c|c|}
\hline Model & $\begin{array}{c}\text { Model } \\
\text { equation }\end{array}$ & $\begin{array}{c}\text { Sample } \\
\text { code }\end{array}$ & $\mathbf{R}^{2}$ \\
\hline \multirow[t]{3}{*}{ Zero order } & \multirow{3}{*}{$Q_{t}=Q_{0}+k_{0} \cdot t$} & A. rusticana & 0.7122 \\
\hline & & AR_L1 & 0.8437 \\
\hline & & AR_L2 & 0.9202 \\
\hline \multirow[t]{3}{*}{ Hixon } & \multirow{3}{*}{$Q_{0}^{1 / 3}-Q^{1 / 3}=k_{H C} \cdot t$} & A. rusticana & 0.7199 \\
\hline & & AR_L1 & 0.9209 \\
\hline & & AR_L2 & 0.9562 \\
\hline \multirow[t]{3}{*}{ Higuchi } & \multirow{3}{*}{$Q=k_{H} \cdot t^{1 / 2}$} & A. rusticana & 0.8696 \\
\hline & & AR_L1 & 0.9555 \\
\hline & & AR_L2 & 0.9747 \\
\hline \multirow[t]{3}{*}{ First order } & \multirow[t]{3}{*}{$\ln \left(Q / Q_{0}\right)=-k_{1} \cdot t$} & A. rusticana & 0.9901 \\
\hline & & AR_L1 & 0.9261 \\
\hline & & AR_L2 & 0.9337 \\
\hline
\end{tabular}

Table 2

RELEASE KINETIC MODELING OF LIPOSOMES LOADED WITH A. RUSTICANA AND FREE EXTRACT. kinetics models were applied (Zero-order, First order, Higuchi and Hixson-Crowell) and the model that best fitted our data was determined by comparison of the correlation coefficient $\left(R^{2}\right)$. It was observed that release from free extract followed an exponential equation (Firstorder), with $\mathrm{R}^{2}>0.99$, while release from liposomal formulations followed a Higuchi model driven mainly by a diffusioncontrolled mechanism $\left(R^{2}>0.95\right)$, results confirmed by other studies [23].

\section{Conclusions}

Liposomes loaded with $A$. rusticanawere prepared using thin-film hydration method and characterizated for entrapment efficiency, size, polydispersity index and stability. Liposomes loaded with $A$. rusticana presented good entrapment efficiency, nano-sizes (lower than 150 $\mathrm{nm})$, narrow polydispersity index and good stability over 90 days at $4^{\circ} \mathrm{C}$. The liposomal formulations reduced burst release of extract and provided a much slower release compared with free extract. These promising results suggest that liposomes could be exploited as carriers for herbal ingredients.

Acknowledgement: This work was supported by Ministery of Research and Innovation CNCS-UEFISCDI, projects PN-III-P1-1.1-PD2016-1756, contract no 74/2018 and 6N/2016-PN-16-27-03-02.

\section{References}

1.ELOY, J. O., DE SOUZA, M. C., PETRILLI, R., BARCELLOS, J. P. A., LEE, R., MARCHETTI, J. M., Colloids Surf. B. Biointerfaces., 123, 2014, p. 345-363.

2.AILIESEI, I., ANUTA, V., MIRCIOIU, C., COJ OCARU, V., ORBESTEANU, A.M., CINTEZA, L.O., Rev. Chim. (Bucharest), 67, no. 8, 2016, p. 15661570.

3.IONESCU, BARRAGAN-MONTERO, MONTERO, Rev. Chim. (Bucharest), 63, no. 4, 2012, p. 412-415.

4.PAUN, V.A., POPA, M., DESBRIERES, J., PEPTU, C.A., DRAGAN, S.V., ZEGAN, G.,CIOCA, G., Mat. Plast., 53, no 4, 2016, p. 590-593.

5.BHATTACHARYA, S., Pharma Times, 41, nr. 3, 2009, p. 9 -12.
6.ENASCUTA，C.E，STEPAN, E., OPRESCU, E.E.,RADU, A., ALEXANDRESCU E., STOICA R.,EPURE D.G., NICULESCU M.D., Rev. Chim. (Bucharest), 69, no. 7, 2018, p. 1612-1615.

7.EFTIMIE TOTU, E., VOICILA, E., PISTRITU, V., NECHIFOR, G., CRISTACHE, C. M., Rev. Chim. (Bucharest), 69, no. 1, 2018, p. 155-159. 8.SARAF, A., Fitoterapia. 81, 2010, p. 680-689.

9.YADAV, M., BHATIA, V., DOSHI, G., SHASTRI, K., Int. J. Pharm. Sci. Rev. Res. 28, nr. 2, 2014, p. 83-89.

10.CHAUHAN, N.S., GOWTHAM, R., GOPALKRISHNA, B., J. Pharm. Res., 2, 2009, p. 1267-1270.

11.SOON, S.K., SUN, Y.K., BONG, J.K., KYEONG, J.K., GEUN, Y.N., NA, R.I., JI, W.L., JI, H.H., JUNOH, K., SOO, N.P., Int. J. Pharm., 483, no. 12, 2015, p. 26-37.

12. GIBIS, M., ZEEB, B., WEISS, J., Food Hydrocoll., 38, 2014, p. 28-39. 13.HE, Z.F., LIU, D.Y., ZENG, S., YE, J.T., 2008. J Chine Mat Med; 33, p. 27-30.

14.BO, R. , X. MA, Y. FENG, Q. ZHU, Y. HUANG, Z. LIU, C. LIU, Z. GAO, Y. HU, D. WANG, Carbohydr. Polym., 117, 2015, p. 215-222.

15.BAI, C., PENG, H., XIONG, H., LIU, Y., ZHAO, L., XIAO, X., Food Chem., 129, no. 4, 2011, p. 1695-1702.

16.CALABRONE, L., LAROCCA, M., MARZOCCO, S., MARTELLI, G., ROSSANO, R. Extracts. Food Nutr. Sci., 6, 2015, p. 64-74.

17.LARA, M. G., BENTLEY, M. V. and COLLETT, J. H., Int J Pharm, 293(1-2), 2005, p. 241-250

18.NIMESH, S., MANCHANDA, R., KUMAR, R., SAXENA, A., CHAUDHARY, P., YADAV, V., MOZUMDAR, S. and CHANDRA, R., Int] Pharm, 323 (12), 2006, p. 146-152.

19.MAKADIA, H. K. and SIEGEL, S. J., Polymers (Basel), 3 (3), 2011, p. 1377-1397.

20.CASTANGIA, I., CADDEO, C., MANCA, M.L., CASU, L., CATALAN LATORRE A., DIEZ-SALES, O., RUIZ-SAURI, A., BACCHETTA, G., FADDA, A.M., MANCONI, M., Carbohydr. Polym., 134, no. 1, 2015, p. 657-663. 21.GIBIS, M., VOGT, E., WEISS, J., Food \& Function, 3, nr. 3, 2012, p. 246-254.

22.GIBIS, M., RAHN, N., WEISS, J., . Pharmaceutics, 5, nr. 3, 2013, p. 421-433.

23.GIBIS, M., RUEDT C., WEISS J ., Food Res. Int., 88, 2016, p. 105-113 